\title{
PENGARUH LAJU ALIRAN UDARA TERHADAP KONSENTRASI KANDUNGAN GAS MAMPU BAKAR DAN DAYA GASIFIKASI
}

\author{
OTONG NURHILAL*, FERRY FAIZAL, HARRY POETRA SOEDARSONO \\ Departemen Fisika Fakultas MIPA Universitas Padjadjaran, \\ Jl. Raya Bandung-Sumedang Km 21,Jatinangor 45363 \\ *email : otong.nurhilal@phys.unpad.ac.id
}

\begin{abstract}
Abstrak. Pada penelitian ini telah dianalisa $\mathrm{CH}_{4}, \mathrm{CO}$ dan $\mathrm{H}_{2}$ sebagai unsur dominan pada gas hasil gasifikasi dari sekam padi dan bonggol jagung. Tipe gasifikator yang digunakan adalah tipe updraft dengan udara sebagai medium gasifikasi dengan variasi laju udara 1-5 m/s. Pengukuran dilakukan dengan menggunakan sensor MQ2, MQ4 dan MQ8. Banyaknya bahan biomassa yang digunakan untuk 1 kali proses gasifikasi adalah $1 \mathrm{~kg}$. Berdasarkan data hasil pengukuran temperatur gasifikasi tertinggi mencapai 866 ${ }^{\circ} \mathrm{C}$ dengan laju aliran udara $4,8 \mathrm{~m} / \mathrm{s}$. Untuk nilai konsentrasi rata-rata $\mathrm{CH}_{4}, \mathrm{CO}$ dan $\mathrm{H}_{2}$ tertinggi untuk bonggol masing masing adalah 3791,4 ppm, 8959,4 ppm, dan 8267,1 ppm dengan laju aliran udara $5 \mathrm{~m} / \mathrm{s}$. Untuk sekam padi diperoleh nilai rata-rata konsentrasi masing-masing adalah 6728 ppm 7497 ppm, dan 7617 ppm pada $3 \mathrm{~m} / \mathrm{s}$. Nilai daya terbesar untuk bonggol jagung adalah $11,6 \mathrm{~kW}$ pada laju aliran $5 \mathrm{~m} / \mathrm{s}$ dan sekam padi adalah $2,51 \mathrm{~kW}$ pada laju aliran $3 \mathrm{~m} / \mathrm{s}$.
\end{abstract}

Kata kunci: gasifikasi, biomassa, konsentrasi, daya

\begin{abstract}
In this study $\mathrm{CH}_{4}, \mathrm{CO}$ and $\mathrm{H}_{2}$ have been analyzed as the dominant element in the gas gasification from rice husks and corncob. The type of gasifier used is the type of updraft with air as a gasification medium with variations in air velocity $1-5 \mathrm{~m} / \mathrm{s}$. Measurements are made using MQ2, MQ4 and MQ8 sensors. The amount of biomass material used for one gasification process is $1 \mathrm{~kg}$. Based on the data of the highest gasification temperature measurements reaching $866{ }^{\circ} \mathrm{C}$ with an air flow rate of $4.8 \mathrm{~m} / \mathrm{s}$. The highest average concentration values of $\mathrm{CH}_{4}, \mathrm{CO}$ and $\mathrm{H}_{2}$ for humps were 3791.4 ppm, $8959.4 \mathrm{ppm}$ and $8267.1 \mathrm{ppm}$ with air flow rates of $5 \mathrm{~m} / \mathrm{s}$. For rice husks, the average concentration values were $6728 \mathrm{ppm} 7497 \mathrm{ppm}$ and $7617 \mathrm{ppm}$ at $3 \mathrm{~m} / \mathrm{s}$, respectively. The greatest power value for corncob is $11.6 \mathrm{~kW}$ at a flow rate of $5 \mathrm{~m} / \mathrm{s}$ and rice husk is $2.51 \mathrm{~kW}$ at a flow rate of $3 \mathrm{~m} / \mathrm{s}$.
\end{abstract}

Keywords: gasification, biomass, concentration, power

\section{Pendahuluan}

Gasifikasi merupakan proses yang menggunakan panas untuk mengubah biomassa padat menjadi gas sintetik mampu bakar. Gas yang dihasilkan pada proses gasifikasi disebut gas produser yang kandungannya didominasi oleh gas $\mathrm{CO}, \mathrm{H}_{2}$ dan $\mathrm{CH}_{4}[1]$. Proses gasifikasi memerlukan medium gasifikasi berupa udara, oksigen dan uap air[2]. Proses gasifikasi bisa dimanfaatkan untuk menghasilkan energi alternatif yang bersumber dari biomassa yang melimpah seperti sekam padi dan bonggol jagung yang diproduksi pertahun masing-masing 57,05 juta ton dan 50,7 juta ton di Indonesia [3]. 
Untuk menghasilkan gas diperlukan reaktor gasifikasi. Produksi gas terjadi pada dua tahapan penting. Tahap pertama adalah reaksi eksotermik oksigen pada udara dengan gas pirolisis dibawah kondisi pengayaan bahan bakar. Tahap kedua adalah reaksi endotermik gas-gas besar $\mathrm{CO}_{2}$ dan $\mathrm{H}_{2} \mathrm{O}$ dengan arang panas (hot char) yang berperang untuk menghasilkan gas seperti $\mathrm{CO}$ dan $\mathrm{H}_{2}$. Tipe reaktor gasifikasi yang sederhana adalah tipe updraft dengan keuntungan antara lain konstruksi yang sederhana dan memiliki efisiensi termal yang tinggi serta bisa digunakan untuk kapasitas kecil maupun besar [4].

Termo-kimia gasifikasi dapat dikelompokkan berdasarkan basis media (agen) gasifikasinya yaitu uap air, udara dan oksigen. Proses gasifikasi dengan medium udara biasanya menghasilkan gas dengan nilai kalor yang rendah. Gas dengan nilai kalor yang tinggi dihasilkan dari oksigen dan uap air sebagai agennya. Namun, untuk memasukkan oksigen dan uap pada reaktor gasifikasi memerlukan biaya yang tinggi serta peralatan khusus [5]. Pada penelitian ini telah dirancang dan diuji reaktor gasifikasi tipe updraft dengan variasi udara sebagai agen dan sekam padi dan bonggol jagung sebagai bahan bakar. Untuk mengukur temperatur dan kandungan gas mampu bakar digunakan termokopel dan sensor berbasis mikrokontroller Arduino.

\section{Metode Penelitian}

Penelitian ini diawali dengan perancangan reaktor gasifikasi yang didasarkan pada beberapa asumsi antara lain ; kebutuhan energi atau daya yang dihasilkan setara dengan $1 \mathrm{kWh}$ [6] dan efisiensi proses gasifikasi $17 \%$ [1]. Berdasarkan data asumsi tersebut dapat ditentukan tinggi dan diameter reaktor gasifikasi. Proses gasifikasi dilakukan dengan memasukkan bahan bakar sebanyak $1 \mathrm{~kg}$. Bahan bakar yang digunakan adalah bonggol jagung dan sekam padi. Pembakaran dimulai dari bagian bawah dengan memberikan pemantik api kemudian memberikan suplai udara yang bervariasi melalui blower kedalam reaktor. Untuk proses pengambilan data temperatur, termokopel ditempatkan pada satu titik di dalam reaktor, sedangkan pengambilan data konsentrasi kandungan gas dilakukan dengan menempatkan tiga sensor gas MQ2, MQ4 dan MQ8 pada tabung penampung gas yang terbentuk. Susunan peralatan gasifikasi ditampilkan pada gambar 1.

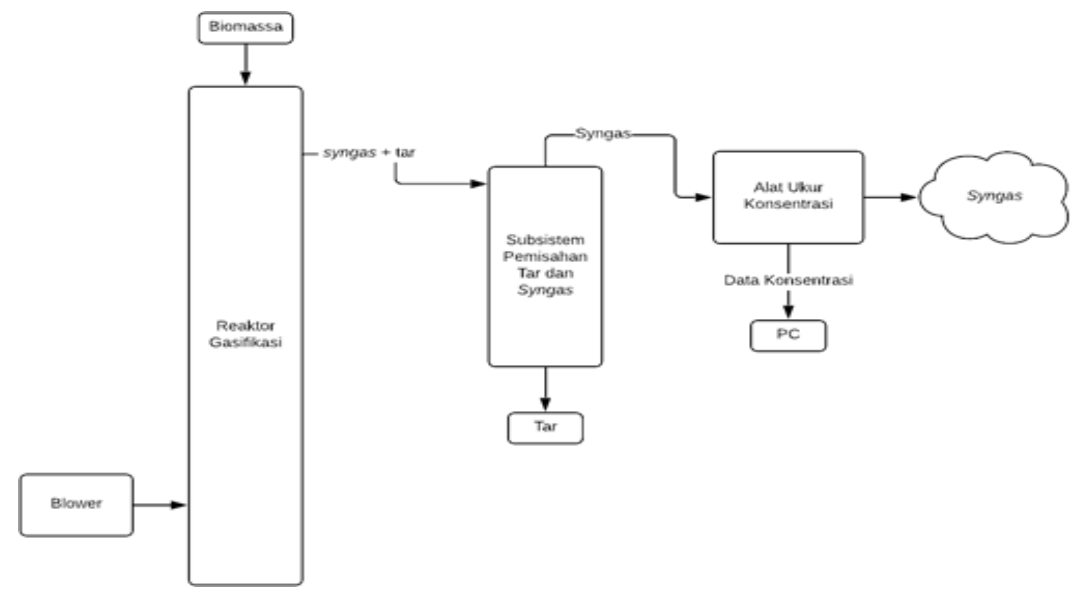

Gambar 1. Susunan peralatan gasifikasi 


\section{Hasil dan Pembahasan}

Hasil perancangan dan proses pengujian ditampilkan pada Gambar 2. Dinding reaktor bagian dalam panjangnya $100 \mathrm{~cm}$, diameter $10,16 \mathrm{~cm}$ dan tebal $2 \mathrm{~mm}$. Dinding rektor luar dengan panjang $80 \mathrm{~cm}$, diamater $15,25 \mathrm{~cm}$ dan tebal $2 \mathrm{~mm}$. Pipa masukan udara dengan panjang $20 \mathrm{~cm}$, diameter $2,54 \mathrm{~cm}$ dan tebal $1 \mathrm{~mm}$. Pipa keluaran gas dengan panjang $20 \mathrm{~cm}$, diameter $2,54 \mathrm{~cm}$ dan tebal $1 \mathrm{~mm}$. Insulasi dinding reaktor dengan panjang $50 \mathrm{~cm}$, lebar $2,54 \mathrm{~cm}$ dan tinggi $80 \mathrm{~cm}$. Reaktor terbuat dari bahan besi sedangkan insulasi terbuat dari keramik. Gambar 2 menampilkan rancangan reactor gasifikasi dan proses gasifikasi.

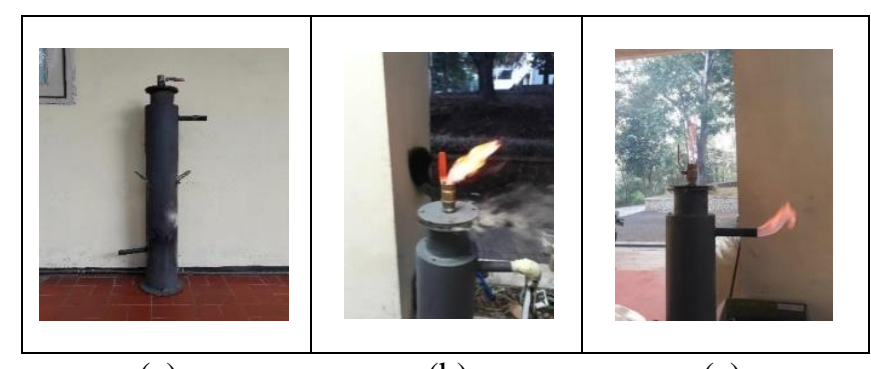

(a)

(b)

(c)

Gambar 2. (a) Reaktor gasifikasi tipe updraft, (b) Lidah api dari tutup atas, (c) Lidah api dari pipa keluaran

\subsection{Pengukuran temperatur}

Pengukuran temperatur dilakukan untuk mengetahui perubahan temperatur pada setiap proses yang meliputi pengeringan, pirolisis dan gasifikasi. Data perubahan temperatur selama proses ditampilkan pada gambar 3 .

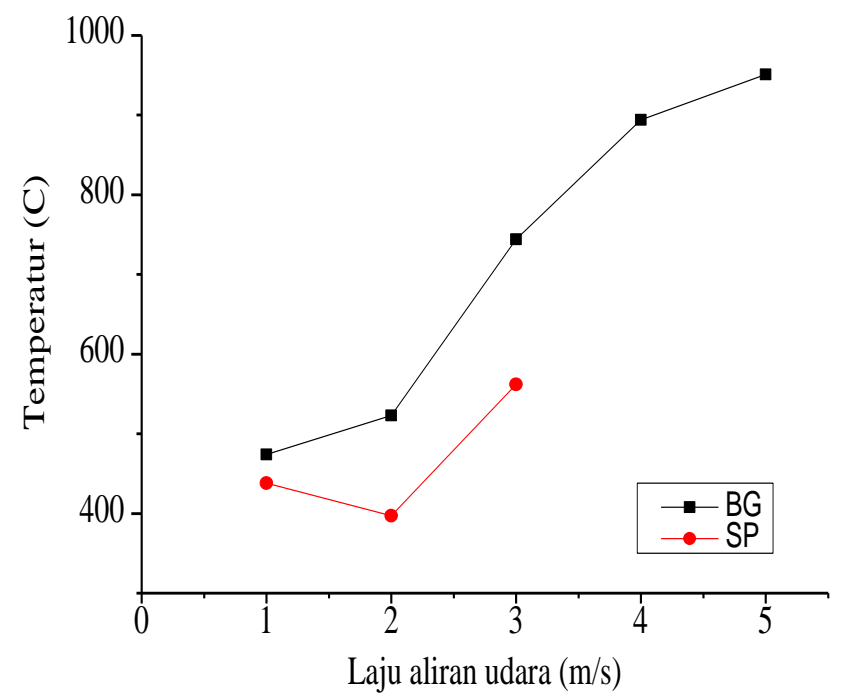

Gambar 3. Pengaruh laju aliran udara terhadap temperatur rata-rata selama proses gasifikasi pada bonggol jagung (BG) dan sekam padi (SP)

Pada gambar 3 temperatur rata-rata gasifikasi bonggol jagung lebih tinggi dari sekam padi. Hal ini disebabkan karena nilai kalor bonggol jagung $(6000 \mathrm{kal} / \mathrm{g})$ 
lebih besar dari nilai kalor sekam padi $(3000 \mathrm{kal} / \mathrm{g})$. Nilai temperatur rata-rata gasifikasi bonggol jagung dan sekam padi untuk laju aliran udara $1 \mathrm{~m} / \mathrm{s}$ tidak berbeda jauh, tetapi untuk laju aliran udara lebih besar dari $1 \mathrm{~m} / \mathrm{s}$ perbedaan temperatur rata-rata kedua bahan biomassa ada perbedaan yang besar. Hal ini disebabkan karena konsentrasi udara yang semakin banyak akan meningkatkan pembakaran dan kenaikan temperature bonggol jagung yang nilai kalornya lebih tinggi dibandingkan sekam padi. Sementara itu, nilai temperature rata-rata sekam padi yang teramati hanya pada laju aliran udara 1-3 m/s. Hal ini disebabkan karena kebocoran yang terjadi pada reaktor gasifikasi.

\subsection{Pengukuran konsentrasi kandungan gas mampu bakar}

Pengukuran konsentrasi kandungan gas mampu bakar diukur dari mulai proses pengeringan, pirolisis hingga gasifikasi. Data konsentrasi kandungan gas diambil dari mulai harga temperatur mendekati temperatur gasifikasi selama waktu tertentu kemudian diambil harga rata-ratanya. Hasil pengukuran konsentrasi $\mathrm{CO}$, $\mathrm{H}_{2}$ dan $\mathrm{CH}_{4}$ terhadap variasi laju aliran udara untuk bonggol jagung dan sekam padi ditampilkan pada gambar 4 .
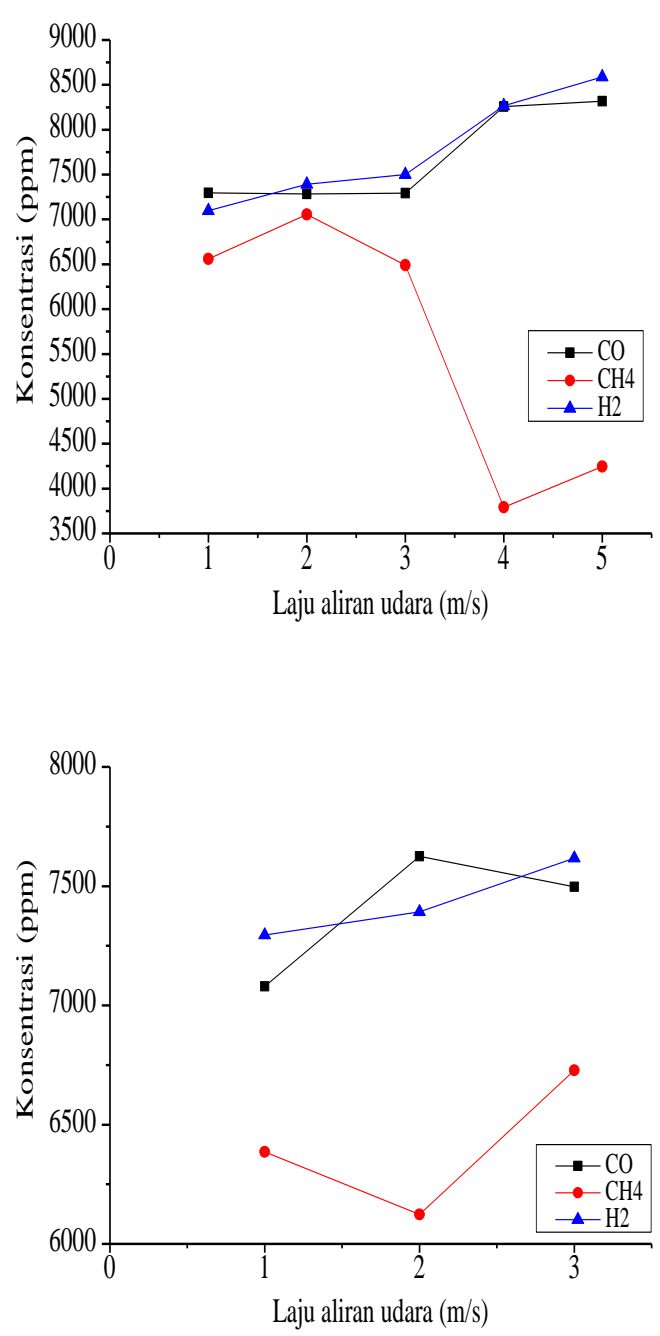

Gambar 4. Grafik konsentrasi $\mathrm{CO}, \mathrm{H}_{2}$, dan $\mathrm{CH}_{4}$ terhadap laju aliran udara untuk bahan biomassa bonggol jagung (atas) dan sekam padi (bawah) 
Berdasarkan gambar 4 peningkatan jumlah konsentrasi gas mampu bakar terjadi pada laju aliran udara lebih besar dari $2 \mathrm{~m} / \mathrm{s}$ khsusunya untuk gas mampu bakar berupa $\mathrm{CO}$ dan $\mathrm{H}_{2}$. $\mathrm{CO}$ dihasilkan dari reaksi $\mathrm{C}$ dengan $\mathrm{O}_{2}$ (reaksi oksidasi) dan $\mathrm{C}$ dengan $\mathrm{CO}_{2}$ (reaksi Boudourd). $\mathrm{H}_{2}$ dihasilkan dari reaksi antara $\mathrm{CO}$ dengan $\mathrm{H}_{2} \mathrm{O}$ (reaksi pergeseran gas udara), dengan $\mathrm{CH}_{4}$ dan dengan $\mathrm{H}_{2} \mathrm{O} . \mathrm{H}_{2}$ juga dihasilkan dari reaksi dan $\mathrm{C}$ dengan $\mathrm{H}_{2} \mathrm{O}$ (reaksi gas air). Sedangkan $\mathrm{CH}_{4}$ dihasilkan dari reaksi antara $\mathrm{C}$ dan $\mathrm{H}_{2}$ (reaksi metanasi). Berdasarkan jumlah reaksi yang terjadi maka konsentrasi $\mathrm{H}_{2}$ lebih besar dari konsentrasi $\mathrm{CO}$ dan $\mathrm{CH}_{4}$. Menurut Belonia gas metana $\left(\mathrm{CH}_{4}\right)$ hanya akan dihasilkan jika reakot gasifikasi beroperasi pada temperature antara 400 sampai $500^{\circ} \mathrm{C}$ [1].

\subsection{Daya gas mampu bakar}

Perhitungan daya yang dihasilkan oleh gas mampu bakar dapat dilakukan dengan cara mengalikan volume komponen gas mampu bakar dengan nilai kalor dari komponen tersebut dibagi waktu gasifikasi. Volume komponenn gas diperoleh dari perkalian konsentrasi total gas dengan debit aliran gas pada pipa keluaran $\left(\mathrm{m}^{3} / \mathrm{s}\right)$ dan dengan 0,72 sebagai faktor koreksi terhadap total komponen gas yang terbentuk. Hasil perhitungan volume komponen gas dari bonggol jagung dengan laju aliran udara $1 \mathrm{~m} / \mathrm{s}$ untuk masing-masing $\mathrm{H}_{2}, \mathrm{CO}$ dan $\mathrm{CH}_{4}$ adalah 31,97 ml, $30,80 \mathrm{ml}$ dan $27,13 \mathrm{ml}$. Dengan cara yang sama diperoleh volume komponen gas dari bonggol jagung dengan laju aliran udara $2-5 \mathrm{~m} / \mathrm{s}$ dan juga unutk sekam padi dengan semua variasi laju aliran udara. Adapun nilai kalor $\mathrm{H}_{2}, \mathrm{CO}$ dan $\mathrm{CH}_{4}$ masing-masing adalah $10788 \mathrm{~kJ} / \mathrm{m}^{3}, 12622 \mathrm{~kJ} / \mathrm{m}^{3}$ dan $35814 \mathrm{~kJ} / \mathrm{m}^{3}$ [7]. Hasil perhitungan daya ditampilkan pada gambar 5 .

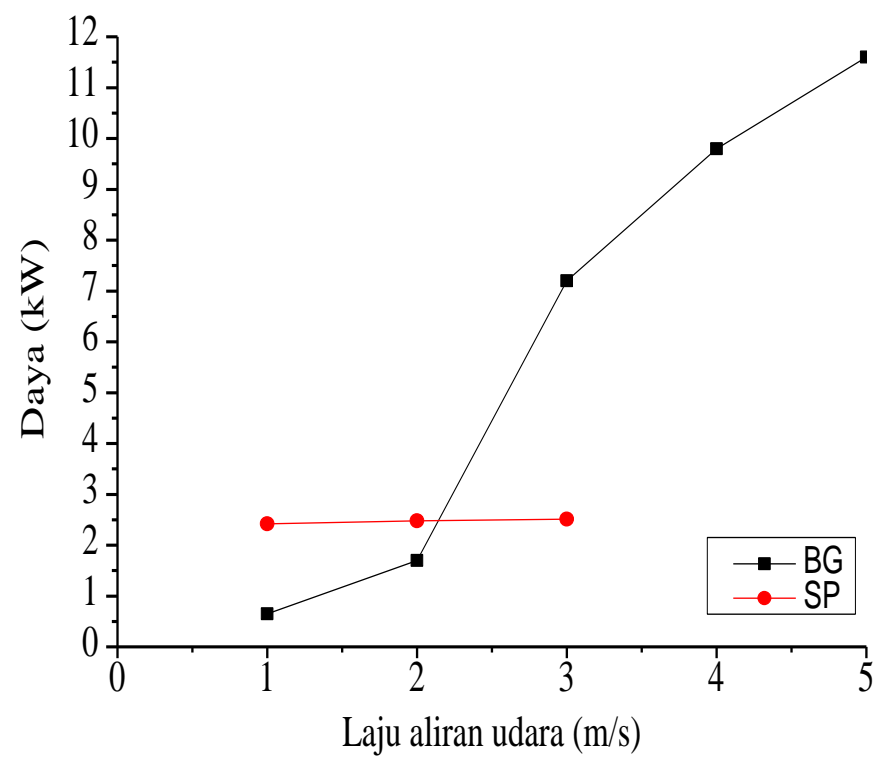

Gambar 5. Kurva daya gas mampu bakar terhadap laju aliran udara

Pada gambar 5 nilai daya gas mampu bakar dari sekam padi tidak ada perbedaan yang besar untuk setiap variasi laju aliran udara. Hal ini sesuai dengan produksi gas mampu bakar yang hampir sama nilainya untuk setiap variasi alju aliran udara seperti pada gambar 4. Demikian pula untuk nilai daya gas mampu bakar dari 
bonggol jagung. Pada nilai daya gas mampu bakar terdapat perbedaan yang besar untuk setiap variasi laju aliran udara.

\subsection{Efisiensi reaktor}

Nilai efisiensi reaktor dihitung dengan membandingkan daya output gas mampu bakar dan daya input bahan bakar saja tanpa memperhitungkan daya listrik yang digunakan untuk menghidupkan blower. Nilai kalor biomassa bonggol jagung sebesar $15.400 \mathrm{~kJ} / \mathrm{kg}$ dan nilai kalor sekam padi $14.400 \mathrm{~kJ} / \mathrm{kg}$.[8]. Nilai efisiensi terhadap laju aliran udara untuk bonggol jagung dan sekam padi ditampilkan pada gambar 6.

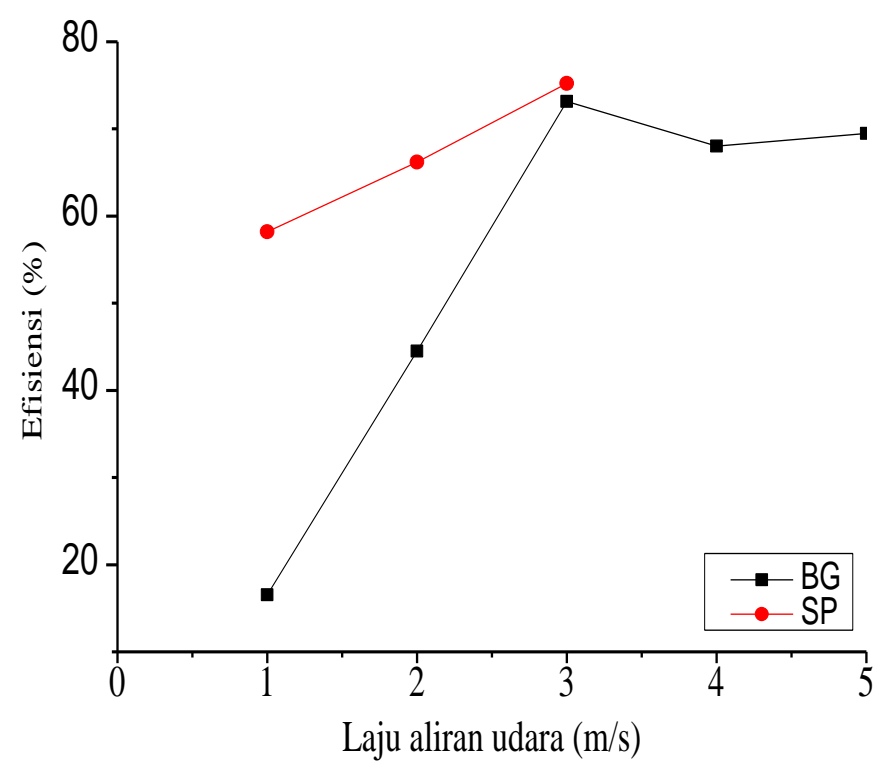

Gambar 6. Kurva efisiensi gasifikasi terhadap laju aliran udara

Pada gambar 6 terlihat nilai efisiensi maksimum terjadi pada laju aliran udara $3 \mathrm{~m} / \mathrm{s}$ yaitu sebesar 75,18\% untuk sekam padi, dan 73,16\% untuk bonggol jagung. Pada laju aliran $3 \mathrm{~m} / \mathrm{s}$ memang daya yang dihasilkan tidak begitu besar apabila dibandingkan dengan laju aliran $4 \mathrm{~m} / \mathrm{s}$ dan $5 \mathrm{~m} / \mathrm{s}$ tetapi lama proses gasifikasi yang berbeda jauh menyebabkan jumlah gas mudah terbakar yang dikeluarkan oleh reaktor menjadi lebih banyak. Penelitian yang dilakukan oleh Alpana Singh, dkk (2015) menghasilkan nilai efisiensi reaktor gasifikasi sebesar 80,04\%[7].

\section{Kesimpulan}

Telah dirancang reaktor gasifikasi tipe updraft dengan temperature gasifikasi mencapai $866{ }^{\circ} \mathrm{C}$ pada laju aliran udara $4,8 \mathrm{~m} / \mathrm{s}$. Selama proses gasifikasi bonggol jagung berlangsung, nilai konsentrasi $\mathrm{CH}_{4}, \mathrm{CO}$ dan $\mathrm{H}_{2}$ paling optimal terjadi pada laju aliran udara $5 \mathrm{~m} / \mathrm{s}$ dengan nilai rata-rata konsentrasi $\mathrm{CH}_{4}$ sebesar 3791,4 ppm, CO sebesar 8959,4 ppm dan $\mathrm{H}_{2}$ sebesar $8267,1 \mathrm{ppm}$. Sementara pada sekam padi didapatkan nilai $\mathrm{CO}$ sebesar $7497 \mathrm{ppm}, \mathrm{CH}_{4}$ sebesar $6728 \mathrm{ppm}$ dan $\mathrm{H}_{2}$ sebesar $7617 \mathrm{ppm}$ pada $3 \mathrm{~m} / \mathrm{s}$. Pengambilan data sekam padi tidak dapat dilakukan pada laju aliran udara diatas $3 \mathrm{~m} / \mathrm{s}$ karena dinding bagian dalam reaktor meleleh saat 
dilakukan percobaan pada laju aliran $5 \mathrm{~m} / \mathrm{s}$ sehingga tidak didapatkan nilai konsentrasi gas mampu bakar.

Dari penelitian ini juga didapat nilai energi gas mampu bakar bonggol jagung dan sekam padi dengan variasi aliran udara $1-5 \mathrm{~m} / \mathrm{s}$. Nilai energi terbesar untuk biomassa bonggol jagung adalah sebesar $11,6 \mathrm{~kW}$ pada laju aliran $5 \mathrm{~m} / \mathrm{s}$ sementara untuk sekam padi didapatkan nilai energi terbesar adalah $2,51 \mathrm{~kW}$ pada laju aliran $3 \mathrm{~m} / \mathrm{s}$. Didapatkan juga nilai efisiensi dari reaktor sebesar 73,16\% untuk bahan biomassa bonggol jagung dengan laju aliran $3 \mathrm{~m} / \mathrm{s}$, dan $75,18 \%$ untuk bahan biomassa sekam padi pada laju aliran $3 \mathrm{~m} / \mathrm{s}$.

\section{Daftar Pustaka}

1. Belonio, Alexis T. Rice Husk Gas Stove Handbook. Philipphins: Central Philippine University, 2005.

2. E. Oveis, S. Sokhansanj, A. Lau, J. Lim, X. Bi, F. Preto, C. Mui. 2018. Characterization of Recycled Wood Chips, Syngas Yield, and Tar Formation in an Industrial Updraft Gasifier. Canada: MDPI Publication.

3. E. Oveisi, S. Sokhansanj, A. Lau, C.J. Lim, X. Bi, M. Ebadian, F. Preto, C. Mui, R. Gill, In-Depot Upgrading The Quality Of Fuel Chips For A Commercial Gasification Plant. Canada : Biomass Bioenergy, Vol. 108 (2018) $138-145$.

4. T. K. Sarkar, M, A, Awal, M. Ahiduzzaman, M. Akhtaruzzaman, M. A. Hossen. Evaluation Of Husk Feeded Modified Updraft Gasifier. J. Eco-friendly Agril. Vol. 5 No. 06 (2012) 61-68.

5. S. Kheawhom, P. Bumroongsri. Modeling of a Small-scale Biomass Updraft Gasifier. J. Chemical Engineering Transaction Vol 37 (2014) 217-222.

6. A. W. Wusana, H. S. Pranolo, G. Noroochadi, L. M. Ratna, Perancangan dan Uji Kinerja Reaktor Gasifikasi Sekam Padi Skala Kecil. Ekuilibrium Vol 9 No 1 (2010) 29-33.

7. A. Singh, N. K. Srivastava, V. Yadav, D. Kumar, Thermodynamics Study and Improving Efficiency of Biomass Gasifier.India : Advance Research in Electrical and Electronic Engineering. Vol. 2. No. 5 (2015) 47 - 51.

8. T. Iskandar, Identifikasi Nilai Kalor Biochar Dari Tongkol Jagung Dan Sekam Padi Pada Proses Pirolisis. Malang, J. Teknik Kimia Vol. 7. No. 1 (2012). 